\title{
One-year change in health status and subsequent outcomes in COPD
}

\author{
Sarah Wilke, ${ }^{1}$ Paul W Jones, ${ }^{2}$ H Müllerova, ${ }^{3}$ Jørgen Vestbo, ${ }^{4,5}$ Ruth Tal-Singer, ${ }^{6}$ \\ Frits ME Franssen, ${ }^{1}$ Alvar Agusti, ${ }^{7}$ Per Bakke, ${ }^{8}$ Peter M Calverley, ${ }^{9}$ \\ Harvey 0 Coxson, ${ }_{1}^{10}$ Courtney Crim, ${ }^{11}$ Lisa D Edwards, ${ }^{11}$ David A Lomas, ${ }^{12}$ \\ William MacNee, ${ }^{13}$ Stephen I Rennard, ${ }^{14}$ Julie C Yates, ${ }^{11}$ Emiel FM Wouters, ${ }^{1,15}$ \\ Martijn A Spruit ${ }^{1,16}$
}

\begin{abstract}
- Additional material is published online only. To view please visit the journal online (http://dx.doi.org/10.1136/ thoraxjn-2014-205697).

For numbered affiliations see end of article.
\end{abstract}

\section{Correspondence to} Sarah Wilke, Department of Research \& Education, CIRO+, Centre of Expertise for Chronic Organ Failure, Hornerheide 1, NM Horn 6085 ,

The Netherlands; sarahwilke@ciro-horn.nl

Received 7 May 2014 Revised 3 February 2015 Accepted 21 February 2015 Published Online First 17 March 2015

\section{CrossMark}

To cite: Wilke $S$, Jones PW, Müllerova $\mathrm{H}$, et al. Thorax 2015;70:420-425.

\begin{abstract}
Background Poor health status has been associated with morbidity and mortality in patients with COPD. To date, the impact of changes in health status on these outcomes remains unknown.

Aims To explore the relationship of clinically relevant changes in health status with exacerbation,

hospitalisation or death in patients with COPD.

Methods Characteristics and health status (St George's Respiratory Questionnaire, SGRQ) were assessed over a period of 3 years in 2138 patients with COPD enrolled in the Evaluation of COPD Longitudinally to Identify Predictive Surrogate Endpoints (ECLIPSE) study: a longitudinal, prospective, observational study. Associations between change in health status ( $=4$ units in SGRQ score) during year 1 and time to first exacerbation, hospitalisation and death during 2-year follow-up were assessed using Kaplan-Meier plots and log-rank test.
\end{abstract}

Results 1832 (85.7\%) patients (age 63.4 \pm 7.0 years, $65.4 \%$ male, $\mathrm{FEV}_{1} 48.7 \pm 15.6 \%$ predicted) underwent assessment at baseline and 1 year. Compared with those who deteriorated, patients with improved or stable health status in year 1 have a lower likelihood of exacerbation (HR 0.78 (95\% Cl 0.67 to 0.89 ), $p<0.001$ and 0.84 ( 0.73 to 0.97 ), $p=0.016$, respectively), hospitalisation (0.72 (0.58 to 0.90$), p=0.004$ and 0.77 (0.62 to 0.96$), p=0.023$, respectively) or dying $(0.61$ (0.39 to 0.95$), p=0.027$ and 0.58 (0.37 to 0.92$)$, $p=0.019$, respectively) during 2 -year follow-up. This effect persisted after stratification for age and the number of exacerbations and hospitalisations during the first year of the study.

Conclusions Patients with stable or improved health status during year 1 of ECLIPSE had a lower likelihood of exacerbation, hospitalisation or dying during 2-year follow-up. Interventions that stabilise and improve health status may also improve outcomes in patients with COPD. Trial registration number NCT00292552, registered at ClinicalTrials.gov.

\section{INTRODUCTION}

Patients with COPD have impaired disease-specific health status ${ }^{1}{ }^{2}$ that may deteriorate over time. ${ }^{3}$ The St George's Respiratory Questionnaire (SGRQ) is a disease-specific health status questionnaire reflecting a broad variety of health impacts in

\section{Key messages}

What is the key question?

- Whether and to what extent do clinically relevant changes in health status affect morbidity and mortality in patients with COPD?

\section{What is the bottom line?}

- Patients with a 1-year improvement or stable health status had a lower likelihood of having an exacerbation, COPD-related hospitalisation or dying during 2-year follow-up compared with those whose health status deteriorated.

\section{Why read on?}

- The current study supports the concept of routine monitoring health status and suggests improving or at least stabilising health status in patients with COPD.

patients with chronic respiratory diseases. ${ }^{4}$ High baseline SGRQ total scores (ie, poor health status) have been associated with an increased number of exacerbations and hospitalisations in patients with COPD. ${ }^{5}$ Moreover, higher baseline SGRQ scores were associated with worse survival. ${ }^{6}$

An increase of four points or more in SGRQ total score can be considered as a meaningful worsening of patient's health status. ${ }^{7}$ To date, it remains unknown whether and to what extent clinically relevant changes in disease-specific health status may affect morbidity and mortality in patients with COPD. Nevertheless, it seems reasonable to hypothesise that a worsening of diseasespecific health status will be associated with worsening of other important health outcomes.

We sought to explore the impact of clinically relevant 1-year changes in SGRQ total scores on the likelihood of having an exacerbation, hospitalisation or dying in patients with COPD, using data from the Evaluation of COPD Longitudinally to Identify Predictive Surrogate Endpoints (ECLIPSE) study. ${ }^{8}$

\section{METHODS}

The ECLIPSE study is a multicentre, longitudinal, prospective 3-year observational study to identify 
novel endpoints in COPD. ${ }^{8}$ Participants were eligible if they were 40-75 years of age, had a smoking history of 10 or more pack-years and a diagnosis of COPD confirmed with postbronchodilator $\mathrm{FEV}_{1} / \mathrm{FVC}<0.7$. Demographic and clinical characteristics were assessed as described before. ${ }^{9}$

\section{Health status}

Disease-specific health status was assessed using the COPDspecific version of the SGRQ (SGRQ-C) to provide SGRQ scores. The SGRQ-C has three domain scores (symptoms, activity and impact) and a total score, ranging from 0 (optimal) to 100 points (worst). ${ }^{4}$ Health status was assessed at baseline, 1, 2 and 3 years. A change of four units in total score is considered as the minimum clinically important difference. ${ }^{10}$ Only the SGRQ total scores are analysed here.

\section{Study outcomes}

Following the initial period of SGRQ total score change determination, during year 1 , the following outcomes were determined: survival (=all-cause mortality), time to first moderate to severe exacerbation and time to first COPD hospitalisation. Exacerbations were defined as events diagnosed by a clinician that led to the prescription of antibiotics and/or corticosteroids and/or to hospitalisation, as described elsewhere. ${ }^{11}$ Hospitalisations were limited to severe exacerbations requiring hospital admissions. In ECLIPSE, adverse outcomes were assessed at each visit plus monthly phone calls. ${ }^{8}$

\section{Statistics}

Categorical variables were described as frequencies. Continuous variables were tested for normality and were described as mean and SD. Only patients who had complete SGRQ data at baseline and at 1-year follow-up were included in the current analyses. To compare baseline characteristics between patients who completed the first year and those who dropped out during that time, an independent sample $t$ test or Mann-Whitney $U$ test was used. Further, baseline characteristics were compared between patients with a clinically significant 1 -year deterioration in SGRQ score ( $\Delta \geq+4$ points), non-clinically significant 1-year change in SGRQ score ( $\Delta-3.99$ to +3.99 points), or a clinically significant 1-year improvement in SGRQ score ( $\Delta \leq-4$ points). Continuous variables were compared using a univariate analysis of variance followed by post hoc least significance difference multiple comparisons or Kruskal-Wallis test followed by MannWhitney $\mathrm{U}$ test, as appropriate. Categorical variables were compared using $\chi^{2}$ tests.

For the study outcomes, events were flagged and time to event observed over a period of 2 years starting after the 1-year assessment. End of observation time was set at day 1060 . Kaplan-Meier plots illustrate a relationship between 1-year change in SGRQ score and study outcomes. Interactions between variables were tested and Kaplan-Meier curves were constructed for the whole group and further stratified by median baseline age ( $>64$ vs $\leq 64$ years) and number of exacerbations ( $<2$ vs $\geq 2$ exacerbations) and hospitalisations ( $<1$ vs $\geq 1$ hospitalisations) during the first year of the study. HRs, accompanied with $95 \%$ CIs, represent the ratio of the hazard rates derived from unadjusted survival analysis. The log-rank test was used for pairwise comparisons between groups.

Kaplan-Meier curves were constructed using GraphPad Prism 5. Statistical analyses were performed using IBM SPSS statistics, V.19.0.

\section{RESULTS}

\section{Baseline characteristics}

A total of 2138 patients with COPD participated in the ECLIPSE study, of whom 1832 (85.7\%) underwent the 1-year assessment. They were mostly men, slightly overweight, had a moderate to severe airflow limitation, an impaired exercise capacity, and an impaired health status (table 1). Symptoms of dyspnoea, depression or fatigue occurred in $52.0 \%, 25.3 \%$ and $73.7 \%$ of patients, respectively.

Patients who completed the 1-year assessment had a significantly better baseline lung function, 6-min walk distance (6MWD), health status and less symptoms compared with those who dropped out during the first year $(n=306$, table 1$)$.

\section{One-year change in health status}

Patients with a 1-year improvement in health status $(n=675$, $36.8 \%$ ) had a worse baseline health status compared with those who remained stable or deteriorated $(n=630$ and $n=527$, respectively; table 2). Age, baseline lung function, 6MWD, modified Medical Research Council (mMRC) dyspnoea grades, depression scores and fatigue scores were comparable between groups.

\section{Exacerbations, hospitalisations and mortality}

During the 2-year follow-up period (years 2 and 3 of the ECLIPSE study), $1234(67.7 \%)$ patients reported an exacerbation; of these,

Table 1 Baseline patient characteristics: first-year completers versus first-year dropout

\begin{tabular}{|c|c|c|}
\hline & $\begin{array}{l}\text { 1st year } \\
\text { completers } \\
\mathrm{N}=1832\end{array}$ & $\begin{array}{l}\text { 1st year } \\
\text { dropouts } \\
\mathrm{N}=306\end{array}$ \\
\hline Age, years & $63.4(7.0)$ & $63.9(7.8)$ \\
\hline Male, n (\%) & $1199(65.4)$ & $195(63.7)$ \\
\hline Current smokers, n (\%) & $659(36.0)$ & $114(37.3)$ \\
\hline $\mathrm{BMI}, \mathrm{kg} / \mathrm{m}^{2} \mathrm{\dagger}$ & $26.0(22.7-29.6)$ & $25.6(22.4-29.5)$ \\
\hline $\mathrm{FEV}_{1}, \%$ predicted $^{\mathrm{a}}$ & $48.7(15.6)^{*}$ & $45.8(16.1)$ \\
\hline $\mathrm{FEV}_{1}, \mathrm{~L}^{\mathrm{a}}$ & $1.4(0.5)^{*}$ & $1.3(0.5)$ \\
\hline FVC, $L^{a}$ & $3.1(0.9)^{*}$ & $2.9(1.0)$ \\
\hline $\mathrm{FEV}_{1} / \mathrm{FVC}(\%)^{\mathrm{a}}$ & $44.9(11.5)$ & $43.8(11.6)$ \\
\hline Exacerbations previous 12 months, nt & $0.9(1.2)$ & $0.9(1.2)$ \\
\hline $6 M W D, m^{b, c}$ & $378(119)^{* *}$ & $324(126)$ \\
\hline mMRC dyspnoea score (\%) $)^{\mathrm{d}, \mathrm{e}}$ & $1.6(1.1)^{\star *}$ & $1.9(1.1)$ \\
\hline BODE index, points $\mathrm{f}^{\mathrm{f} g}$ & $3.1(2.1)^{* *}$ & $3.8(2.3)$ \\
\hline CES-D score, pointsh, & $11.2(9.3)^{* *}$ & $13.2(9.3)$ \\
\hline FACIT score, points ${ }^{\mathrm{j}, \mathrm{k}}$ & $35.4(10.6)^{* *}$ & $33.1(10.7)$ \\
\hline SGRQ symptom score, points' & $60.1(21.5)^{* *}$ & $64.8(21.1)$ \\
\hline SGRQ activity score, points ${ }^{m}$ & $61.8(21.9)^{* *}$ & $68.3(20.9)$ \\
\hline SGRQ impact score, points ${ }^{n}$ & $35.5(19.3)^{* *}$ & $39.8(20.0)$ \\
\hline SGRQ total score, points ${ }^{\circ}$ & $47.6(18.3)^{* *}$ & $52.7(18.2)$ \\
\hline
\end{tabular}

Values expressed as mean (SD), median ( $25 \%-75 \%$ percentile) or number of patients (n), proportion (\%).

${ }^{*} \mathrm{p} \leq 0.05 ;{ }^{* *} \mathrm{p} \leq 0.001$.

†Non-parametric tests were used for skewed data.

${ }^{a} n=1828$ ('1st year completers'), ${ }^{b} n=1791$ ('1st year completers'), ${ }^{c} n=298$ ('1st year dropout'), ${ }^{d} n=1787$ ('1st year completers'), ${ }^{e} n=285$ ('1st year dropout'), ${ }^{f} n=1743$ ('1st year completers'), ${ }^{9} \mathrm{n}=292$ ('1st year dropout'); ${ }^{\mathrm{h}} \mathrm{n}=1801$ ('1st year completers'), in=297 ('1st year dropout'); ${ }_{n=1794}$ ('1st year completers'), ${ }_{n=293}$ ('1st year dropout'), 'n=281 ('1st year dropout'), ${ }^{m} n=251$ ('1st year dropout'), $n=249$ ('1st year dropout'), ${ }^{\circ} \mathrm{n}=229$ ('1st year dropout').

$\mathrm{BMI}$, body mass index; $\mathrm{FEV}_{1}$, forced expiratory volume in the first second; FVC, forced vital capacity; 6MWD, 6-minute walk distance; mMRC, modified Medical Research Council dyspnoea scale; BODE, body mass index, airway obstruction, dyspnoea, and exercise tolerance; CES-D, Center for Epidemiologic Studies Depression Scale; FACIT, Functional Assessment of Chronic Illness Therapy fatigue scale; SGRQ, St George's Respiratory Questionnaire. 
Table 2 Baseline patient characteristics

\begin{tabular}{|c|c|c|c|c|}
\hline & \multirow[b]{2}{*}{$\begin{array}{l}\text { Whole group } \\
(n=1832)\end{array}$} & \multicolumn{3}{|l|}{ SGRQ total score } \\
\hline & & $\begin{array}{l}\text { Improvement } \\
(\Delta \leq-4 \text { points }) \\
(n=675)\end{array}$ & $\begin{array}{l}\text { No change } \\
(\Delta=-3.99 \text { to } 3.99) \\
(n=630)\end{array}$ & $\begin{array}{l}\text { Deterioration } \\
(\Delta \geq 4 \text { points) } \\
(n=527)\end{array}$ \\
\hline Age, years & $63.4(7.0)$ & $63.0(7.0)$ & $63.6(7.1)$ & $63.6(6.9)$ \\
\hline Male, n (\%) & $1199(65.4)$ & $438(64.9)$ & $411(65.2)$ & $350(66.4)$ \\
\hline Current smokers, n (\%) & $659(36.0)$ & $258(38.2)^{*}$ & $202(32.1)^{* *}$ & $199(37.8)$ \\
\hline BMI, $\mathrm{kg} / \mathrm{m}^{2} \dagger$ & $26.0(22.7-29.6)$ & $25.9(22.9-29.3)$ & $26.5(23.2-29.9)^{* *}$ & $25.6(22.1-29.6)$ \\
\hline $\mathrm{FEV}_{1}, \%$ predicted ${ }^{\mathrm{a}, \mathrm{b}}$ & $48.7(15.6)$ & $48.8(15.2)$ & $49.3(15.9)$ & $47.7(15.7)$ \\
\hline $\mathrm{FEV}_{1}, \mathrm{~L}^{\mathrm{a}, \mathrm{b}}$ & $1.4(0.5)$ & $1.4(0.5)$ & $1.4(0.6)$ & $1.3(0.5)$ \\
\hline FVC, $L^{a, b}$ & $3.1(0.9)$ & $3.1(0.9)$ & $3.1(0.9)$ & $3.0(0.9)$ \\
\hline $\mathrm{FEV}_{1} / \mathrm{FVC}(\%)^{\mathrm{a}, \mathrm{b}}$ & $44.9(11.5)$ & $44.9(11.4)$ & $45.6(11.8)$ & $44.1(11.4)$ \\
\hline Exacerbations previous 12 months, nt & $0.9(1.2)$ & $0.8(1.2)$ & $0.9(1.3)$ & $0.9(1.2)$ \\
\hline $6 M W D, m^{c, d, e}$ & $378(119)$ & $382(112)$ & $378(127)$ & $371(118)$ \\
\hline mMRC dyspnoea score $(\%)^{f, g, h, i}$ & $1.6(1.1)$ & $1.7(1.0)$ & $1.7(1.1)$ & $1.6(1.1)$ \\
\hline BODE index, points $s^{\mathrm{j}, \mathrm{k}, \mathrm{l}, \mathrm{m}}$ & $3.1(2.1)$ & $3.0(1.9)$ & $3.1(2.2)$ & $3.2(2.1)$ \\
\hline CES-D score, points ${ }^{n, o, p, q}$ & $11.2(9.3)$ & $11.7(9.3)$ & $10.9(9.2)$ & $10.7(9.3)$ \\
\hline FACIT score, points, ${ }^{\mathrm{i}, \mathrm{h}, \mathrm{r}}$ & $35.4(10.6)$ & $34.8(10.5)$ & $35.6(11.0)$ & $36.0(10.3)$ \\
\hline SGRQ symptom score, points & $60.1(21.5)$ & $64.1(20.4)^{*, * *}$ & $58.5(21.9)$ & $56.7(21.5)$ \\
\hline SGRQ activity score, points & $61.8(21.9)$ & $65.5(19.6)^{*, * *}$ & $60.3(23.7)$ & $58.8(21.8)$ \\
\hline SGRQ impact score, points & $35.5(19.3)$ & $40.0(18.8)^{*, * *}$ & $34.7(20.3)^{* *}$ & $30.9(17.4)$ \\
\hline SGRQ total score, points & $47.6(18.3)$ & $51.8(16.9)^{*, * *}$ & $46.4(19.7)^{* *}$ & $43.6(17.1)$ \\
\hline One-year change SGRQ total score, points & $-1.3(10.7)$ & $-11.8(7.5)^{* * * *}$ & $0.3(2.3)^{* *}$ & $10.7(5.9)$ \\
\hline \multicolumn{5}{|c|}{ 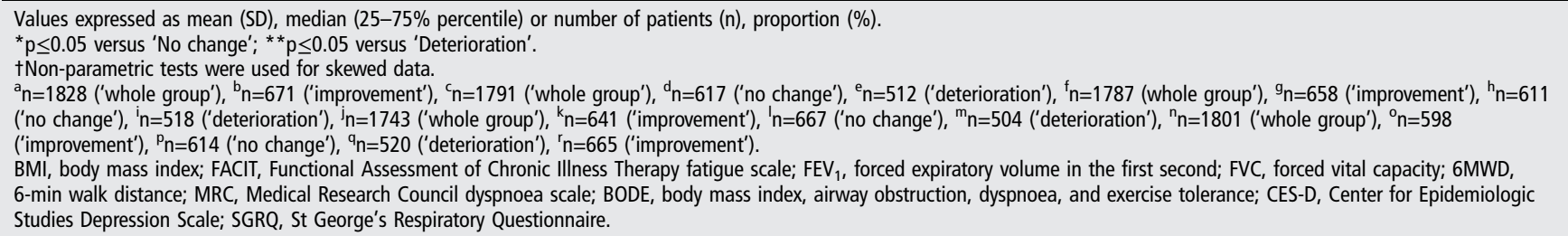 } \\
\hline
\end{tabular}

hospitalisation occurred in 486 (26.7\%) patients. There were 113 (6.2\%) deaths during 2-year follow-up, with an average time to death of 754 (183) days from baseline assessment.

Patients with a 1-year improvement had better survival than those who deteriorated $(\mathrm{HR}=0.61,95 \%$ CI 0.39 to 0.95 , $\mathrm{p}=0.027)$, similarly those who remained stable had better survival $(\mathrm{HR}=0.58,95 \%$ CI 0.37 to $0.92, \mathrm{p}=0.019$ vs deterioration; figure $1 \mathrm{~A}$ and table 3). Patients who improved or remained stable also had a lower likelihood of having a hospitalisation $(\mathrm{HR}=0.72,95 \% \mathrm{CI} 0.58$ to $0.90, \mathrm{p}=0.004$ improvement vs deterioration; $\mathrm{HR}=0.77,95 \% \mathrm{CI} 0.62$ to 0.96 , $\mathrm{p}=0.023$ no change vs deterioration; figure $1 \mathrm{~B}$ and table 3 ). A similar observation was noted with risk of exacerbation $(\mathrm{HR}=0.78,95 \% \mathrm{CI} 0.67$ to $0.89, \mathrm{p}<0.001$ improvement vs deterioration; $\mathrm{HR}=0.84,95 \% \mathrm{CI} 0.73$ to $0.97, \mathrm{p}=0.016$ no change vs deterioration; figure $1 \mathrm{C}$ and table 3 ). The association between 1-year change in health status and exacerbation, hospitalisation and dying was affected by age and number of exacerbations and hospitalisations during year 1. Nevertheless, patients with a 1-year deterioration in health status had worst outcomes in most scenarios (see figure 1, online supplementary figures E1-E3 and table E1). The results retrieved from the SGRQ total score are comparable with the results retrieved from the SGRQ impact domain scores (see online supplementary Figure E4 and table E2).

\section{DISCUSSION}

This is the first study exploring the association between changes in health status and the likelihood of having an exacerbation, hospitalisation and dying in a large cohort of patients with
COPD. Patients with a 1-year improvement or stable health status had a lower likelihood of having an exacerbation, hospitalisation or dying compared with patients who worsened.

Recent studies have identified numerous determinants of change in health status, ${ }^{12-14}$ but knowledge about the importance of such changes is scarce. In the current study, patients with a deterioration in health status during 1 year had a higher chance of an exacerbation, hospitalisation or dying during 2 years of follow-up. These findings support the recommendation by the GOLD committee to include the improvement of health status as an objective in COPD management. ${ }^{15}$ As stated before,

'health status measurement is a means of quantifying, in a standardised and objective manner, the impact of disease on patients' daily life, health, and wellbeing. It is a process that is essentially similar to a highly structured clinical history, although the end product is not a clinical impression but an objective measurement that can be used for scientific purposes. It is no more "soft" or

"touchy-feely" than any well taken clinical history'. ${ }^{16}$

The current study suggests a prognostic role for health status measurement that may help professionals to identify patients at increased risk of adverse health events.

The current study showed that the results retrieved from the SGRQ total score are comparable with those retrieved from the SGRQ impact domain score. This is not surprising since the SGRQ impact domain score behaves in a similar way to the total score whereas the SGRQ symptom domain score has been identified as the weakest correlate with overall health. The SGRQ impact domain covers aspects concerning social functioning and psychological disturbances related to the disease. It is 
A

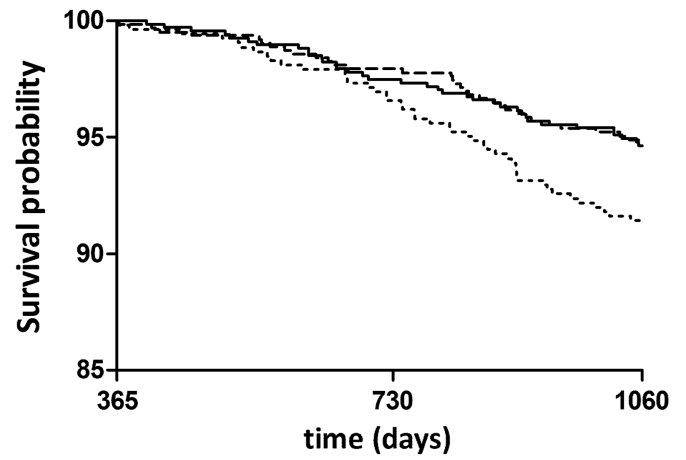

B
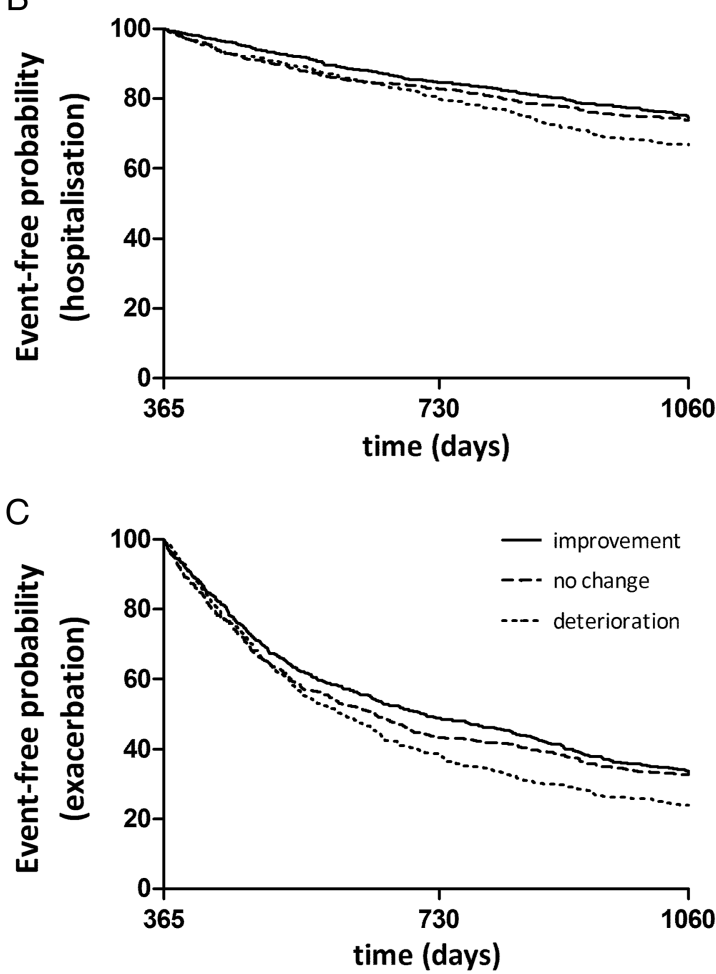

Figure 1 Impact of 1-year change in disease-specific health status on (A) mortality ( $n=1832)$, (B) hospitalisation ( $n=1823)$ and (C) exacerbation $(n=1823)$.

the broadest domain with the most items that correlates best with outcomes in COPD. ${ }^{17}$ Thus, health status is rather a measure of the impact of the disease and the illness perception of the patient than a measure of general well-being. For instance, a previous study showed that patients with a poor health status were more likely to be referred to the respiratory

Table 3 HRs, accompanied with $95 \% \mathrm{Cls}$ for the whole group

\begin{tabular}{|c|c|c|c|}
\hline & \multicolumn{3}{|l|}{ HR $(95 \% \mathrm{Cl})$} \\
\hline & $\begin{array}{l}\text { Improvement vs } \\
\text { no change }\end{array}$ & $\begin{array}{l}\text { No change vs } \\
\text { deterioration }\end{array}$ & $\begin{array}{l}\text { Improvement vs } \\
\text { deterioration }\end{array}$ \\
\hline & SGRQ total score & & \\
\hline Survival & 1.05 (0.65 to 1.69$)$ & $0.58(0.37$ to 0.92$)$ & 0.61 (0.39 to 0.95$)$ \\
\hline Hospitalisation & 0.94 (0.76 to 1.17$)$ & $0.77(0.62$ to 0.97$)$ & $0.72(0.58$ to 0.90$)$ \\
\hline Exacerbation & 0.93 (0.82 to 1.07$)$ & $0.84(0.73$ to 0.97$)$ & $0.78(0.67$ to 0.89$)$ \\
\hline
\end{tabular}

specialist. ${ }^{18}$ Furthermore, patients whose health status improved had a decreased consultation and hospitalisation rate. ${ }^{19}$ Consequently, health status may be closely related to selfmanagement and coping strategies. Indeed, patients with COPD specified coping as a relevant component of health status. ${ }^{20}$ Previously, psychological distress and difficulty in coping with their disease has been shown to impact mortality in patients with severe COPD. ${ }^{21}$ Therefore, self-regulation could significantly assist participants to control their individual symptoms and avoid acute exacerbations. ${ }^{22}$ Consequently, a worsening in health status may be associated with important health outcomes, such as hospitalisation and death. The current study demonstrates that patients' perceptions and changes of patients' perceptions about their health as assessed by SGRQ can play a meaningful role in COPD prognosis.

These data suggest that monitoring for trends in health status over time are important, but they are confined to health status measured using the SGRQ, which is too complex for use in routine practice. However there is already evidence that the shorter instruments such as the COPD Assessment Test, which were designed for routine use, can also predict exacerbations in patients already known to be at high risk. ${ }^{23}$

Even in younger patients (age $\leq 64$ years) whose health status deteriorated during the first year, there was a greater risk of dying or an exacerbation compared with patients whose health status remained stable or improved. Bentsen and colleagues ${ }^{24}$ recently showed that younger patients and those with higher anxiety scores reported worse health status. The authors explained this phenomenon by the fact that younger patients are still learning how to cope with their disease and that older patients experience functional impairment more often as a part of getting older. ${ }^{24}$ In the current study, younger patients reported significantly higher Center for Epidemiologic Studies Depression Scale scores (ie, more symptoms of depression) and worse health status at baseline compared with older patients (see online supplementary table E3). The current study underlines the importance to pay special attention to the health status of younger patients with COPD and their perceptions of the impact of the disease.

COPD as a leading cause of death is increasing ${ }^{25}$ and the economic burden of the disease is substantial. ${ }^{26-28}$ Indeed, COPD exacerbations requiring hospitalisation are a 'major cost driver ${ }^{28}$ that continue to increase. ${ }^{27}$ Consequently, prognostic measurements for the progression of the disease are important. Moreover, prevention and early treatment of exacerbations are needed. The current study indicates a need for assessing health status as a possible part of exacerbation prevention strategies. Furthermore, the current study supports the interest in stabilising or enhancing health status in patients with COPD. A previous study showed that frequent exacerbations are related to poor health status. ${ }^{29}$ Since the current study identified a decline in health status as a contributing risk factor for getting an exacerbation, even after stratification for the exacerbation and hospitalisation frequency during year 1 , it is important to interrupt this vicious circle and intervene on time. Stabilising and/or improving health status can be achieved by providing optimal pharmacological ${ }^{30}$ medical $/$ surgical ${ }^{31}$ and non-pharmacological treatment, including pulmonary rehabilitation. ${ }^{32}$ Finally, the enhancement of patient's compliance with treatment is important since patients who withdrew from treatment showed a more rapid decline in health status. ${ }^{33}$ However, since health status shares causative factors with other outcomes reflecting different processes, it is important to recognise that treatments resulting in improved health status will also have similar effects on other mechanisms. 
Although the ECLIPSE study is a multicentre, longitudinal, prospective 3-year study that included a large number of patients worldwide, thus allowing an in-depth characterisation of the COPD population, there are relevant limitations that should be taken into account. First, the study consisted of a convenience sample of secondary care patients. Patients were eligible if they had moderate to very severe COPD, excluding patients with mild airflow limitation (GOLD stage I). Furthermore, patients who reported a better health status at baseline had a greater chance to worsen during 1-year follow-up and vice versa. Consequently, part of the effect of change in health status could be explained by a statistical artefact such as regression to the mean; ${ }^{34}$ however, that would not explain the association between change in health status and the other outcomes. Moreover, there was no interaction between change in SGRQ score and baseline SGRQ score. Finally, the current findings need to be interpreted in the light of the number of comparisons that were made in the present study. ${ }^{35}$ Nonetheless, multiple findings in the same direction, rather than a single statistically significant result, suggest that these are not due to chance alone.

To conclude, ECLIPSE COPD subjects with a 1-year improvement or stable health status had a lower likelihood of having an exacerbation, hospitalisation or dying during 2-year follow-up compared with those whose health status deteriorated. The current study supports the concept of routine monitoring health status of patients with COPD with the aim of improving or at least stabilising their health status.

\footnotetext{
Author affiliations

${ }^{1}$ Department of Research \& Education, CIRO+, Centre of Expertise for Chronic Organ Failure, Horn, The Netherlands

${ }^{2}$ Division of Clinical Science, St George's University of London, London, UK

${ }^{3}$ Respiratory Epidemiology, GlaxoSmithKline, Uxbridge, UK

${ }^{4}$ Department of Respiratory Medicine, Gentofte Hospital Hellerup, Gentofte, Denmark

${ }^{5}$ Research Group, Manchester Academic Health Sciences Centre, University Hospital South Manchester NHS Foundation, Manchester, UK

${ }^{6}$ Research and Development, GlaxoSmithKline, King of Prussia, UK

${ }^{7}$ Thorax Institute, Hospital Clinic, IDIBAPS, Universitat de Barcelona and CIBER Enfermedades Respiratorias (CIBERES), Barcelona, Spain

${ }^{8}$ Department of Thoracic Medicine, Institute of Clinical Science, University of Bergen, Haukeland University Hospital, Bergen, Norway

${ }^{9}$ Division of Infection and Immunity Clinical Sciences Centre, University Hospital Aintree, Liverpool, UK

${ }^{10}$ Department of Radiology, Vancouver General Hospital, University of British

Columbia, Vancouver, Canada

${ }^{11}$ GlaxoSmithKline, Research Triangle Park, North Carolina, USA

${ }_{12}^{12}$ Wolfson Institute for Biomedical Research, University College London, London, UK

${ }^{13} \mathrm{MRC}$ Centre for Inflammation Research, The Queen's Medical Research Institute,

University of Edinburgh, Edingburgh, UK

${ }^{14}$ Division of Pulmonary, Critical Care, Sleep \& Allergy, University of Nebraska

Medical Center, Omaha, USA

${ }^{15}$ Department of Respiratory Medicine, Maastricht University Medical Centre, Maastricht, The Netherlands

${ }^{16}$ Faculty of Medicine and Life Sciences, REVAL-Rehabilitation Research Center, BIOMED_Biomedical Research Institute, Hasselt University, Diepenbeek, Belgium
}

Acknowledgements The present authors are grateful to statistician Nicholas Locantore for arranging data management and data transfer.

Contributors Conception and design, SW, PWJ, HM, FMEF, EFMW, MAS. Drafting of the manuscript, SW, MAS. Acquisition and analysis of data, SW, PWJ, HM, FMEF, EFMW, MAS. Analysis and interpretation of data, SW, PWJ, HM, FMEF, EFMW, MAS. Drafting the manuscript for important intellectual content, all authors. All authors critically revised the article and gave final approval of this version to be published.

Funding ECLIPSE was sponsored by GlaxoSmithKline (NCT00292552, SC0104960); SW was supported by funding from GlaxoSmithKline (SC0115406) and Lung Foundation Netherlands (3.4.10.015).

Competing interests PWJ did not receive any payment or services from a third party for any aspect of the submitted work, but reports grants and personal fees from GlaxoSmithKline, personal fees from Novartis, Almirall, Pearl and Jannsen and his university received consulting fees for work that he performed for Novartis (outside the submitted work). HM is an employee of GlaxoSmithKline R\&D and owns shares and stock options of GlaxoSmithKline PIc. JV has been reimbursed by GlaxoSmithKline, AstraZeneca, Boehringer-Ingelheim, Chiesi, Novartis, Pfizer and Takeda for presenting at various meetings, and has been a paid advisor for GlaxoSmithKline, AstraZeneca, Boehringer-Ingelheim, Chiesi and Novartis. RT-S, CC, $\mathrm{LDE}$ and JCY are employees and shareholders at GlaxoSmithKline. AA reports grants and/or personal fees from GlaxoSmithKline, Almiral, Boehringer Ingelheim, AstraZeneca, Esteve, Novartis, Nycomed and Roche. PMC received consulting fees, lecture fees, and travel support from Novartis, GlaxoSmithKline, Boehringer Ingelheim, and Takeda (outside the submitted work). HOC has received an honorarium for serving on the steering committee for the ECLIPSE project for GSK; was the co-investigator on two multicentre studies sponsored by GlaxoSmithKline and has received travel expenses to attend meetings related to the project; had contract service agreements with GlaxoSmithKline to quantify the CT scans in subjects with COPD and has a service agreement with Spiration Inc to measure changes in lung volume in subjects with severe emphysema. DAL received grant support, consultancy fees and honoraria from GlaxoSmithKline. WM reports personal fees from Pfizer, Almirall, GlaxoSmithKline, Novartis, Janssen, AstraZeneca, Boehringer Ingelheim; grants from British Heart Foundation, Chief Scientist Office, MRC (outside the submitted work). SIR has served as a consultant or participated in advisory boards for: AARC, American Board of Internal Medicine, Able Associates, Align2 Acton, Almirall, APT, AstraZeneca, American Thoracic Society, Beilenson, Boehringer Ingelheim, Chiesi, CIPLA, Clarus Acuity, CME Incite, COPDFoundation, Cory Paeth, CSA, CSL Behring, CTS Carmel, Dailchi Sankyo, Decision Resources, Dunn Group, Easton Associates, Elevation Pharma, FirstWord, Forest, GLG Research, Gilead, Globe Life Sciences, GlaxoSmithKline, Guidepoint, Health Advance, HealthStar, HSC Medical Education, Johnson and Johnson, Leerink Swan, LEK, McKinsey, Medical Knowledge, Medimmune, Merck, Navigant, Novartis, Nycomed, Osterman, Pearl, PeerVoice, Penn Technology, Pennside, Pfizer, Prescott, Pro Ed Communications, PriMed, Pulmatrix, Quadrant, Regeneron, Saatchi and Saatchi, Sankyo, Schering, Schlesinger Associates, Shaw Science, Strategic North, Summer Street Research, Synapse, Takeda, Telecon SC, ThinkEquity. EFMW did not receive any payment or services from a third party for any aspect of the submitted work, but reports grants and/or personal fees from Nycomed, AstraZeneca,

GlaxoSmithKline and Novartis (outside the submitted work).

Ethics approval ECLIPSE complies with the Declaration of Helsinki and Good Clinical Practice Guidelines, and has been approved by the ethics committees of the participating centres

Provenance and peer review Not commissioned; internally peer reviewed.

\section{REFERENCES}

1 Spruit MA, Pennings HJ, Janssen PP, et al. Extra-pulmonary features in COPD patients entering rehabilitation after stratification for MRC dyspnea grade. Respir Med 2007:101:2454-63.

2 Wilke $S$, Janssen DJ, Wouters EF, et al. Correlations between disease-specific and generic health status questionnaires in patients with advanced COPD: a one-year observational study. Health Qual Life Outcomes 2012;10:98.

3 Habraken JM, van der Wal WM, Ter Riet G, et al. Health-related quality of life and functional status in end-stage COPD: a longitudinal study. Eur Respir J $2011 \cdot 37: 280-8$

4 Jones PW, Quirk FH, Baveystock CM, et al. A self-complete measure of health status for chronic airflow limitation. The St. George's Respiratory Questionnaire. Am Rev Respir Dis 1992:145:1321-7.

5 Yorgancioglu A, Havlucu Y, Celik P, et al. Relation between quality of life and morbidity and mortality in COPD patients: two-year follow-up study. COPD 2010;7:248-53

6 Domingo-Salvany A, Lamarca R, Ferrer M, et al. Health-related quality of life and mortality in male patients with chronic obstructive pulmonary disease. Am J Respir Crit Care Med 2002;166:680-5.

7 Jones PW. St. George's Respiratory Questionnaire: MCID. COPD 2005;2:75-9.

8 Vestbo J, Anderson W, Coxson HO, et al. Evaluation of COPD Longitudinally to Identify Predictive Surrogate End-points (ECLIPSE). Eur Respir J 2008;31:869-73.

9 Spruit MA, Watkins ML, Edwards LD, et al. Determinants of poor 6-min walking distance in patients with COPD: the ECLIPSE cohort. Respir Med 2010;104:849-57.

10 Jones PW. Interpreting thresholds for a clinically significant change in health status in asthma and COPD. Eur Respir J 2002;19:398-404.

11 Hurst JR, Vestbo J, Anzueto A, et al. Susceptibility to exacerbation in chronic obstructive pulmonary disease. N Engl J Med 2010;363:1128-38.

12 Monteagudo M, Rodriguez-Blanco T, Llagostera M, et al. Factors associated with changes in quality of life of COPD patients: a prospective study in primary care. Respir Med 2013;107:1589-97.

13 Rolink M, van Dijk W, van den Haak-Rongen S, et al. Using the DOSE index to predict changes in health status of patients with COPD: a prospective cohort study. Prim Care Respir 2013;22:169-74. 
14 Wilke S, Spruit MA, Wouters EF, et al. Determinants of 1-year changes in disease-specific health status in patients with advanced chronic obstructive pulmonary disease: a 1-year observational study. Int J Nurs Pract 2014 Published Online First: 26 Mar 2014. doi:10.1111/ijn.12265

15 Vestbo J, Hurd SS, Agusti AG, et al. Global strategy for the diagnosis, management, and prevention of chronic obstructive pulmonary disease: GOLD executive summary. Am J Respir Crit Care Med 2013;187:347-65.

16 Jones PW. Health status measurement in chronic obstructive pulmonary disease. Thorax 2001;56:880-7.

17 Jones PW, Quirk FH, Baveystock CM. The St George's Respiratory Questionnaire. Respir Med 1991;85(Suppl B):25-31.

18 Osman IM, Godden DJ, Friend JA, et al. Quality of life and hospital re-admission in patients with chronic obstructive pulmonary disease. Thorax 1997;52:67-71.

19 Cox NJ, Hendricks JC, Binkhorst RA, et al. A pulmonary rehabilitation program for patients with asthma and mild chronic obstructive pulmonary diseases (COPD). Lung 1993;171:235-44.

20 Paap $M$, Bode $C$, Lenferink $L$, et al. Identifying key domains of health-related quality of life for patients with chronic obstructive pulmonary disease: the patient perspective. Health Qual Life Outcomes 2014;12:106.

21 Ashutosh K, Haldipur C, Boucher ML. Clinical and personality profiles and survival in patients with COPD. Chest 1997;111:95-8.

22 Kuo CC, Lin CC, Lin SY, et al. Effects of self-regulation protocol on physiological and psychological measures in patients with chronic obstructive pulmonary disease. J Clin Nurs 2013;22:2800-11.

23 Lee SD, Huang MS, Kang J, et al. The COPD Assessment Test (CAT) assists prediction of COPD exacerbations in high-risk patients. Respir Med 2014; 108:600-8
24 Bentsen SB, Miaskowski C, Rustoen T. Demographic and clinical characteristics associated with quality of life in patients with chronic obstructive pulmonary disease. Qual Life Res 2014;23:991-8.

25 Hurd $S$. The impact of COPD on lung health worldwide: epidemiology and incidence. Chest 2000;117(2 Suppl):1S-4S

26 Perera PN, Armstrong EP, Sherrill DL, et al. Acute exacerbations of COPD in the United States: inpatient burden and predictors of costs and mortality. COPD 2012;9:131-41.

27 Blanchette CM, Dalal AA, Mapel D. Changes in COPD demographics and costs over 20 years. J Med Econ 2012;15:1176-82.

28 Teo WS, Tan WS, Chong WF, et al. Economic burden of chronic obstructive pulmonary disease. Respirology 2012;17:120-6.

29 Mackay AJ, Donaldson GC, Patel AR, et al. Usefulness of the Chronic Obstructive Pulmonary Disease Assessment Test to evaluate severity of COPD exacerbations. Am J Respir Crit Care Med 2012;185:1218-24.

30 Spencer S, Calverley PM, Burge PS, et al. Impact of preventing exacerbations on deterioration of health status in COPD. Eur Respir J 2004;23:698-702.

31 Benzo R, Farrell MH, Chang CC, et al. Integrating health status and survival data: the palliative effect of lung volume reduction surgery. Am J Respir Crit Care Med 2009;180:239-46.

32 Spruit MA, Singh SJ, Garvey C, et al. An official American Thoracic Society/European Respiratory Society statement: key concepts and advances in pulmonary rehabilitation. Am J Respir Crit Care Med 2013;188:e13-64.

33 Calverley PM, Spencer $S$, Willits $L$, et al. Withdrawal from treatment as an outcome in the ISOLDE study of COPD. Chest 2003;124:1350-6.

34 Barnett AG, van der Pols JC, Dobson AJ. Regression to the mean: what it is and how to deal with it. Int J Epidemiol 2005;34:215-20.

35 Perneger TV. What's wrong with Bonferroni adjustments. BMJ 1998;316:1236-8. 